\title{
In-Situ Transmission Electron Microscope: Joule Heating Effect on Graphitisation of Copper Incorporated Carbon Nanofiber
}

\author{
M. 'Azizir-Rahim', M. Z. M. Yusop"1,2*, M.H.D. Othman², M. Ibrahim³ and \\ M. Tanemura ${ }^{3}$ \\ ${ }^{1}$ Department of Materials, School of Mechanical Engineering, Faculty of Engineering, \\ Universiti Teknologi Malaysia, 81310 Skudai, Johor, Malaysia \\ ${ }^{2}$ Advanced Membrane Technology Research Centre, Universiti Teknologi Malaysia, \\ 81310 Skudai, Johor, Malaysia \\ ${ }^{3}$ Department of Frontier Materials, Nagoya Institute of Technology, \\ Gokiso-cho, Showa-ku, Nagoya, 466-8555 Japan \\ *Email: zamriyusop@utm.my
}

\begin{abstract}
The Joule heating process on copper $(\mathrm{Cu})$ incorporated carbon nanofiber was observed carefully under the in-situ transmission electron microscope (TEM) facilities. A significant structural formation occurred after the Joule heating process showing a single crystalline encapsulated graphitic structure with dramatic improvement on graphitic structure of carbon nanofiber from amorphous to crystalline. The latter structure is knowingly similar to multilayered graphene structure. This $\mathrm{Cu}$ incorporated carbon nanofiber initially was shaped by the mixture of amorphous carbon and very fine crystalline $\mathrm{Cu}$ structure which was significantly changed by the effect of applied bias voltage. The change of $\mathrm{Cu}$ particles crystallinity also shows the importance of crystalline structure for the graphene formation. The in-situ TEM results provide useful information on the formation of graphene and the solid phase reaction which is interesting and vital in graphene synthesis mechanism.
\end{abstract}

Keywords: In-situ TEM observation; ion irradiation method; carbon nanofiber; Joule heating

\section{INTRODUCTION}

Carbon nanomaterials such as carbon nanotubes, carbon nanofibers and graphene have attracted significant interest as efficient electron emitters due to their potential application in future flat panel displays, electron beam instruments and x-ray sources [1-7]. There are several advantages of carbon nanomaterials-based electron emitters such as high aspect ratio, sharp tip and chemical inertness leading to the restrain of applied voltage to emit electrons even at low vacuum pressure [8-12]. In general, carbon nanotubes and graphene are usually synthesised at high temperature process [13-19]. On the contrary, ion-induced carbon nanofibers can be fabricated at low temperature, or even at room temperature. Recent progresses have shown that ion-induced carbon nanofibers can be directly fabricated on a transparent polymer surface and copper plate [20-26]. Due to exceptional amorphous properties of carbon nanofibers, the fabrication of carbon nanofibers usually does not need complex temperature treatment nor annealing process. Graphene have similar synthesis method like carbon nanotubes which usually require high temperature process. The growth mechanism of carbon nanotubes and graphene still requires a detailed explanation in order to obtain perfectly desired properties of carbon nanotubes and graphene. The observation of 
graphitic structure of carbon nanotubes and graphene can be only performed under a powerful microscope such as TEM and scanning transmission electrons microscope (STEM) which is capable to observe at atomic scale. However, the growth formation layer by layer of carbon nanotubes and graphene can be only observed by in-situ TEM facilities that require external piezo devices equipped in the special TEM holder. In a previous work, the authors have discussed the formation of carbon nanotube from carbon nanofiber using in-situ facilities during field emission process using $\mathrm{Fe}$ incorporated carbon nanofiber [27]. Moreover, the Joule heating occurred on pristine carbon nanofiber showing improvement on graphitic properties and electrical properties [28]. The authors believed that the graphitic formation could be controlled by in-situ TEM facilities. Hence, in this work the authors challenged direct observation of graphene layers formation from $\mathrm{Cu}$ incorporated carbon nanofiber using in-situ TEM facilities.

\section{EXPERIMENTAL SETUP}

A Kaufmann-type ion gun (Iontech. Inc. Ltd., model 3-1500-100FC) was used for growing carbon nanofibers. Samples employed were commercially available $\mathrm{Cu}$ foils having a size of $5 \mathrm{~mm} \times 10 \mathrm{~mm} \times 100 \mu \mathrm{m}$ and the edge of the foils were irradiated with argon ion $\left(\mathrm{Ar}^{+}\right)$ ions at room temperature. The growth mechanism of ion-induced carbon nanofibers was explained elsewhere in detail [29]. For the $\mathrm{Cu}$ incorporated carbon nanofibers growth, an additional graphite plate, having a size of $15 \mathrm{~mm} \times 10 \mathrm{~mm} \times 1 \mathrm{~mm}$, as a $C$ supply was placed horizontally adjacent to the $\mathrm{Cu}$ foil and they were co-irradiated with $\mathrm{Ar}^{+}$at $45^{\circ}$ from the normal to the surface for 45 minutes at room temperature (Figure 1). The oblique $\mathrm{Ar}^{+}$ bombardment is known to be more suitable for the growth of ion-induced carbon nanofibers than normal incidence [30-32]. The diameter and ion beam energy employed for this experiment were $6 \mathrm{~cm}$ and $1 \mathrm{keV}$, respectively. The basal and working pressures were $1.5 \times$ $10^{-5}$ and $2.0 \times 10^{-2} \mathrm{~Pa}$, respectively.

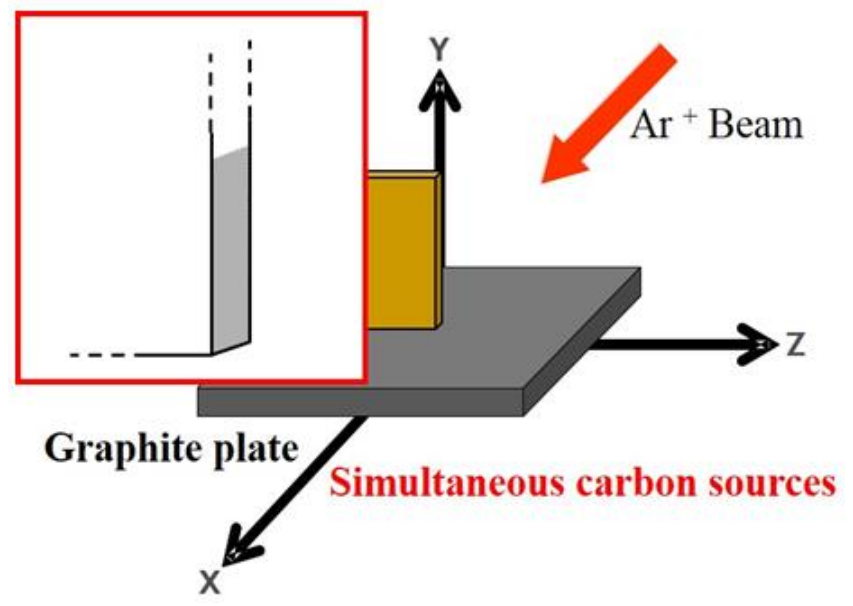

Figure 1. Schematic diagram of sample setup. The inset shows the marked area where carbon nanofibers were mostly grown

After sputtering, the morphology of the $\mathrm{Cu}$ incorporated carbon nanofibers grown on the edge of the $\mathrm{Cu}$ foils was carefully observed by a scanning electron microscope [SEM (JEOL JSM-5600)] and the crystallinity of the sample was examined by TEM (JEOL JEM2010). A custom-made TEM sample holder (JEOL; EM - Z02154T) was used with a piezocontrolled tungsten $(\mathrm{W})$ nanoprobe coated with gold $(\mathrm{Au})$ to apply a bias voltage maintained 
at $200 \mathrm{mV}$ with additional $200 \mathrm{k} \Omega$ on the $\mathrm{Cu}$ carbon nanofiber sample. The piezo-controlled nanoprobe were free to move in $\mathrm{x}, \mathrm{y}, \mathrm{z}$ axis directions controlled by the DC power system. The $\mathrm{Cu}$ foil was cut into a $2 \mathrm{~mm}$ width and directly mounted on the TEM sample holder without any other post treatment.

\section{RESULTS AND DISCUSSION}

Figure 2 shows the SEM image of $\mathrm{Cu}$ incorporated carbon nanofibers after ion irradiation. It should be noted that only $\mathrm{Cu}$ carbon nanofibers grew on respective cones and no carbon nanofibers grew without cone bases. The carbon nanofiber was vibrating due to the electrons charge effect from the TEM electron beam. During structure observation, this problem was overcome by contacting the nanoprobe with the carbon nanofiber's tip.

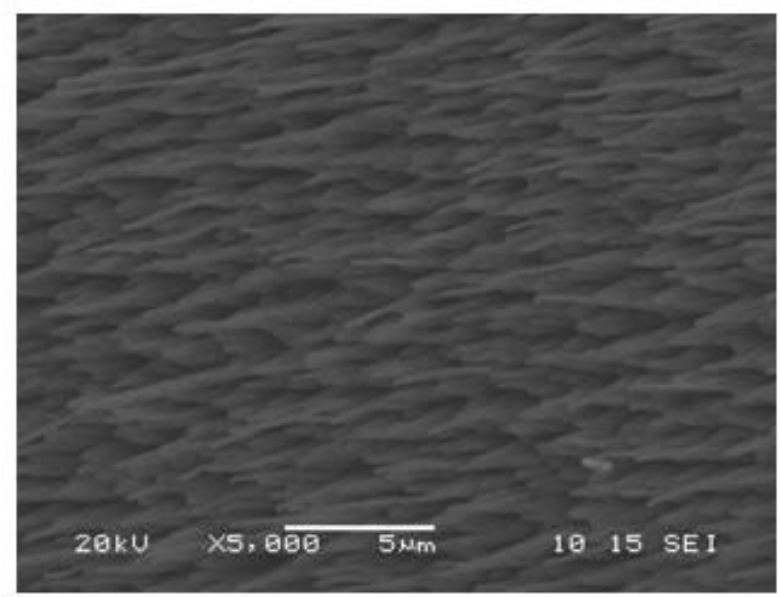

Figure 2. The SEM image of the morphology of $\mathrm{Cu}$ incorporated carbon nanofibers at the $\mathrm{Cu}$ foil edge after $\mathrm{Ar}^{+}$ion bombardment

Figures 3(a) - 3(c) show the TEM images of $\mathrm{Cu}$ incorporated carbon nanofibers. The $\mathrm{Cu}$ incorporated carbon nanofibers were approximately $1 \mu \mathrm{m}$ in length and $200 \mathrm{~nm}$ in diameter (Figure 3(a)). The inset image shows the selected area electron diffraction (SAED) pattern of the $\mathrm{Cu}$ incorporated carbon nanofiber. From the SAED pattern results it shows that $\mathrm{Cu}$ incorporated carbon nanofiber consists of dominant diffraction spots of $\mathrm{C} 120, \mathrm{C}$ 010, $\mathrm{Cu} 111$ and $\mathrm{Cu} 220$. Figure 3(b) shows the fibrous structures of the $\mathrm{Cu}$ incorporated carbon nanofiber at high magnification at the fibre part revealing dispersion of several polycrystalline nanostructures in the amorphous carbon matrix. Further investigation of dark field images from SAED pattern indicated that $\mathrm{Cu}$ particles dispersed randomly in the amorphous carbon structure.

To investigate the structures transformations of $\mathrm{Cu}$ incorporated carbon nanofibers by bias voltage; a low applied bias voltage at $200 \mathrm{mV}$ flow was applied on $\mathrm{Cu}$ incorporated carbon nanofiber with additional $200 \mathrm{k} \Omega$ external resistor. The external resistor helped to reduce the shock damage at the carbon nanofiber tip during the applied bias voltage, hence a proper structural transformation was observable. The sample was observed at $\times 30 \mathrm{k}$ magnification on TEM. The gold ( $\mathrm{Au}$ ) coated tungsten $(\mathrm{W})$ nanoprobe was slowly controlled by a piezo driver to touch the $\mathrm{Cu}$ incorporated carbon nanofiber tip. This also helped to stabilise the carbon nanofiber tip during the image capture process. The pressure in the specimen chamber was about $10^{-5} \mathrm{~Pa}$ during the applied bias. The structural transformation was captured using a CCD device and recorded using a computer software. It was noted that 
during the applied bias voltage the TEM beam concentration was lowered at a minimum level to make sure it would not directly affect to experiment. The $\mathrm{Cu}$ incorporated carbon nanofiber was transformed instantaneously after the applied bias voltage. The initial structure of $\mathrm{Cu}$ particles was assuming as very fine crystalline (in Figure 3(c)) and mixed with the amorphous structure of carbon atoms. After the bias voltage the $\mathrm{Cu}$ particles changed to a specific crystal structure, $\mathrm{Cu}$ (111) with carbon graphitic arranged at the outer layer. This indicates that fine graphene can only form on a specific crystal structure such as $\mathrm{Cu}(111)$.
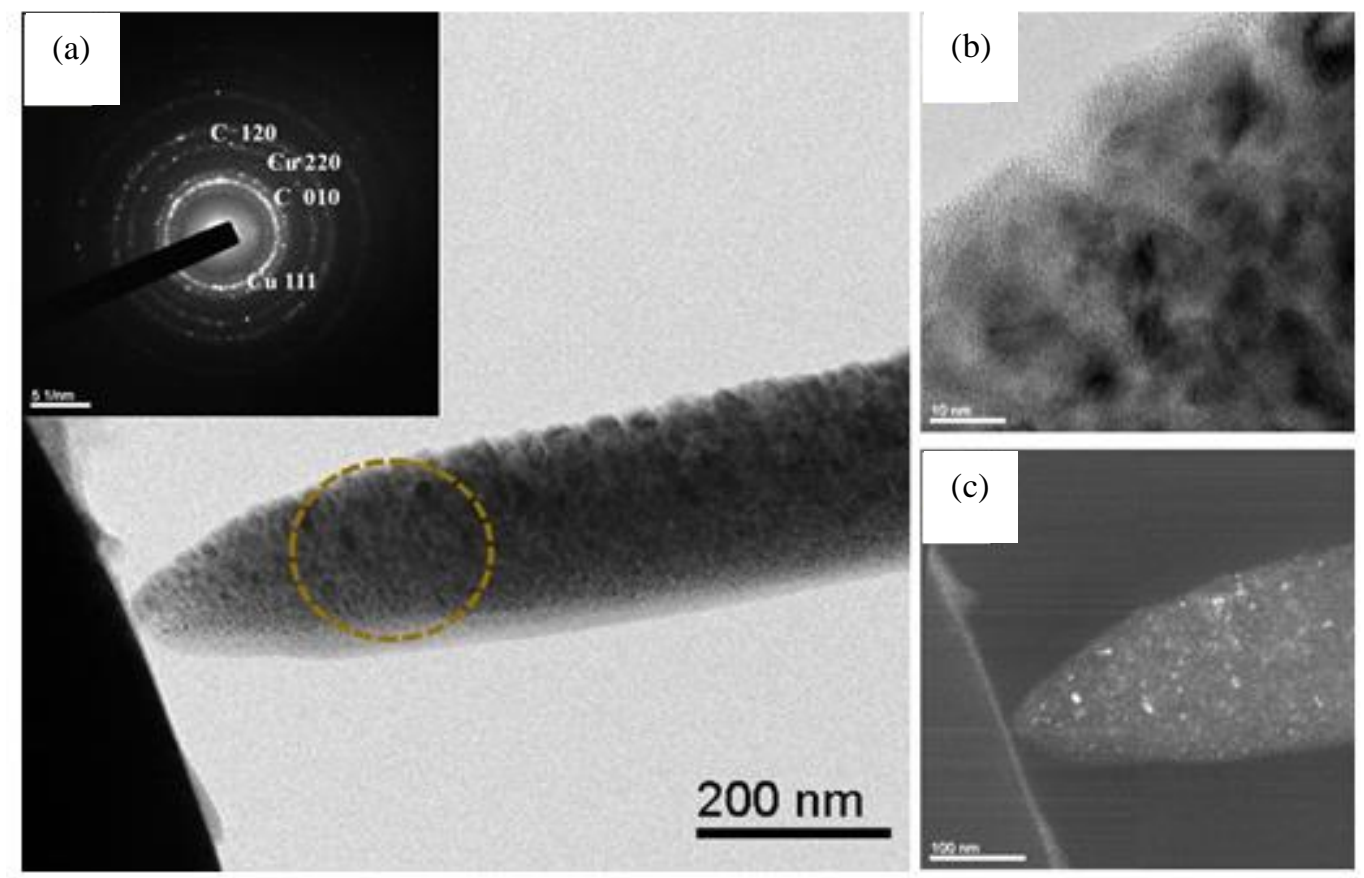

Figure 3. (a) TEM image of the intact structure of $\mathrm{Cu}$ incorporated carbon nanofiber before bias voltage (inset shows the selected area of diffraction pattern), (b) high magnification of TEM image of the fibre showing polycrystalline structure dispersed in amorphous carbon and; (c) dark field image showing the distribution of $\mathrm{Cu}$ particles in carbon amorphous structure.

Figure 4(a) to 4(d) shows the $\mathrm{Cu}$ incorporated carbon nanofiber structure after the applied bias voltage. The $\mathrm{Cu}$ incorporated carbon nanofiber significantly transformed into single crystalline particles encapsulated by graphitic layers after applying the bias voltage due to the induced Joule heating. The $\mathrm{Cu}$ nanoparticles from the fibre part of $\mathrm{Cu}$ incorporated carbon nanofiber agglomerated into huge sphere-like particles whilst amorphous carbon transformed into graphitic layers surrounding the agglomerated $\mathrm{Cu}$ particles as in Figure 4(a). This statement is proven by the SAED pattern of round shape particles that clearly showed diffraction spots of single crystals of $\mathrm{Cu} 111$ in Figure 4(b). For further investigation, the bright field of the latter particle was taken using the SAED spot clearly indicating the graphitic formation covering the crystalline structure in Figure 4(c). Finally, we can reconfirm the crystalline area of the $\mathrm{Cu} 111$ diffraction spots (JCPDS: 04-0836) in Figure 4(b) from the dark field image in Figure 4(d). From Figure 4(a) - 4(d) it is understood that the induced Joule heating caused the $\mathrm{Cu}$ nanoparticles that randomly dispersed in the fibrous structure to agglomerate and form into a large single crystalline structure of $\mathrm{Cu} 111$. Both 
SAED pattern and dark field images also reconfirm that this result is not influenced from the neighbouring carbon nanofiber part.

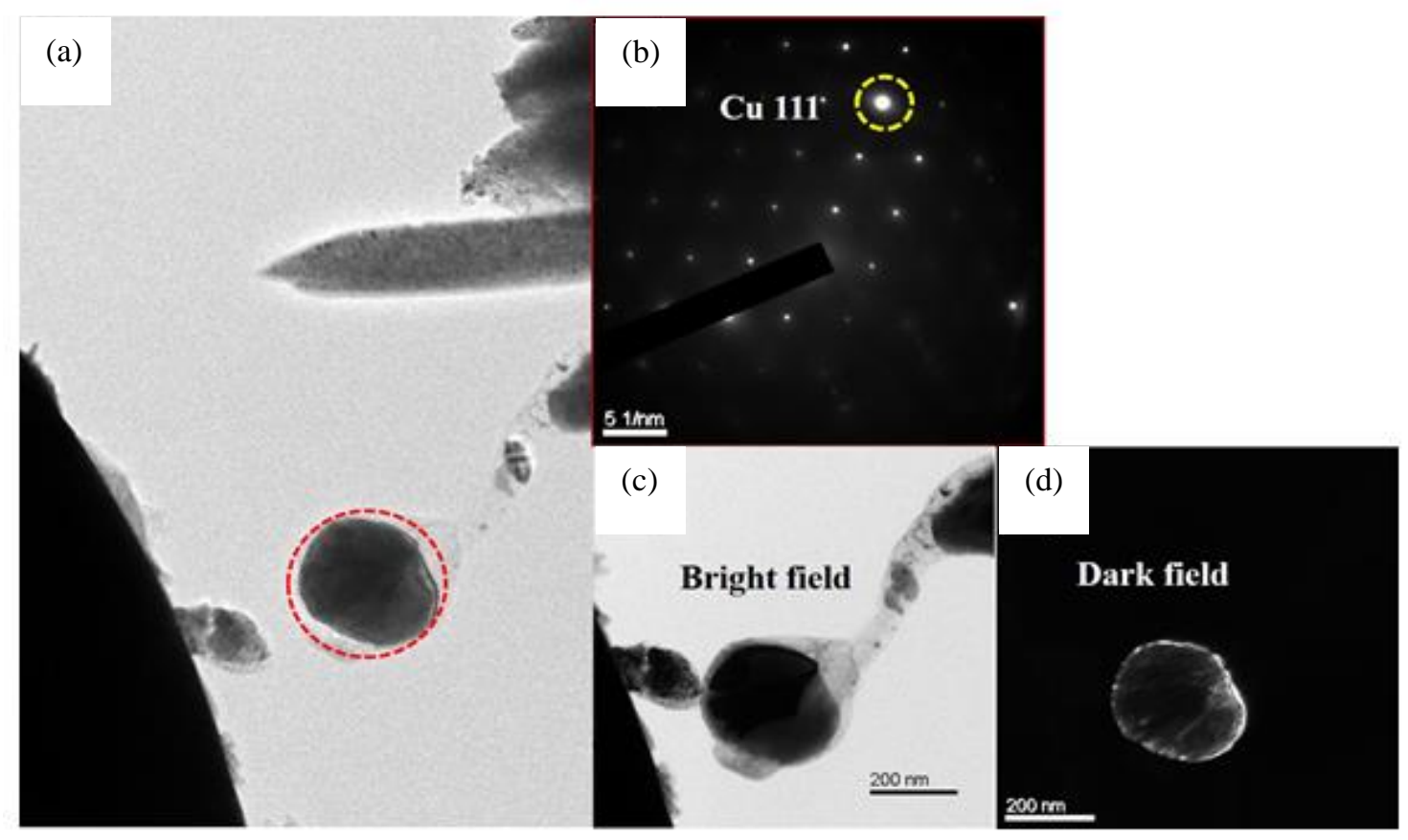

Figure 4. (a) TEM image of $\mathrm{Cu}$ incorporated carbon nanofiber after bias voltage, (b) SAED pattern area marked in Figure 4(a) showing crystalline structure of $\mathrm{Cu} 111$, (c) bright field image from the SAED results clearly indicating metal crystalline (dark region) covered by graphitic layers formation (bright region) and; (d) dark field image from the SAED result clearly showing area of the crystalline diffraction point of Figure 4(b)

Figure 5(a) to 5(f) shows the high magnification TEM of the graphitic layers formation of Figure 4(a). From this result it is understood that most of the graphitic layers are around 10-13 nm as shown in Figure 5 (a), (c) and (e). However, a few samples show thin layers of graphene in less than two layers, as shown in Figure 5(f). Figure 5(d) shows very fine formation of 10 layers of graphitic structure.

Figure 6 shows the distance profile result indicating that the layers thickness is around $0.34 \mathrm{~nm}$. This lattice distance value is similar to the graphene thickness (JCPDS No. 75-1621) from which we can confirm the formation of bright region in the TEM is graphitic layers formation. The distance profile also shows that the thickness formation is the same for each layer which confirms there is no other carbide formation in the bright region.

In order to understand the effect of the Joule heating from the bias voltage we need to estimate the temperature rise during the applied voltage. According to Vincent et al., the temperature rise of one dimensional object during the current flow can be estimated using a resistive heating model [33]. For a one-dimensional object like carbon nanofiber, the temperature distribution equation is expressed as follows:

$$
\Delta T(K)=T_{L}(K)-T_{O}(K)=\frac{R L I^{2}}{2 K A}
$$

where $R$ is metal resistivity of carbon nanotubes/ carbon nanofibers $\left(3.85 \times 10^{-5} \Omega . \mathrm{m}\right), K$ is thermal conductivity $(20 \mathrm{~W} / \mathrm{mK}), A=\pi \mathrm{r}^{2}$, cross sectional area of a carbon nanofiber and $I$ is 
current flow. In our present experiment, the length and radius of carbon nanofiber`s tip were found to be 1000 and $10 \mathrm{~nm}$, respectively. The current flow was up to $1 \mu \mathrm{A}$. The current would flow along the carbon nanofiber from the tip part through the outer surface and hence most of the structural change would occur from the outer layers [29], [34]. If the outer layer thickness is assumed to be $0.34 \mathrm{~nm}$ (corresponding to 1 layer thickness of graphene), the temperature of the outer layer during the applied bias voltage estimated from the above Eq. (1) would have reached $4.92 \times 10^{+2} \mathrm{~K}$, which would satisfy the recrystallisation temperature of carbon nanofiber structure. So, generation of Joule heating during the applied bias voltage would be responsible for the structural change of the $\mathrm{Cu}$ incorporated carbon nanofiber.

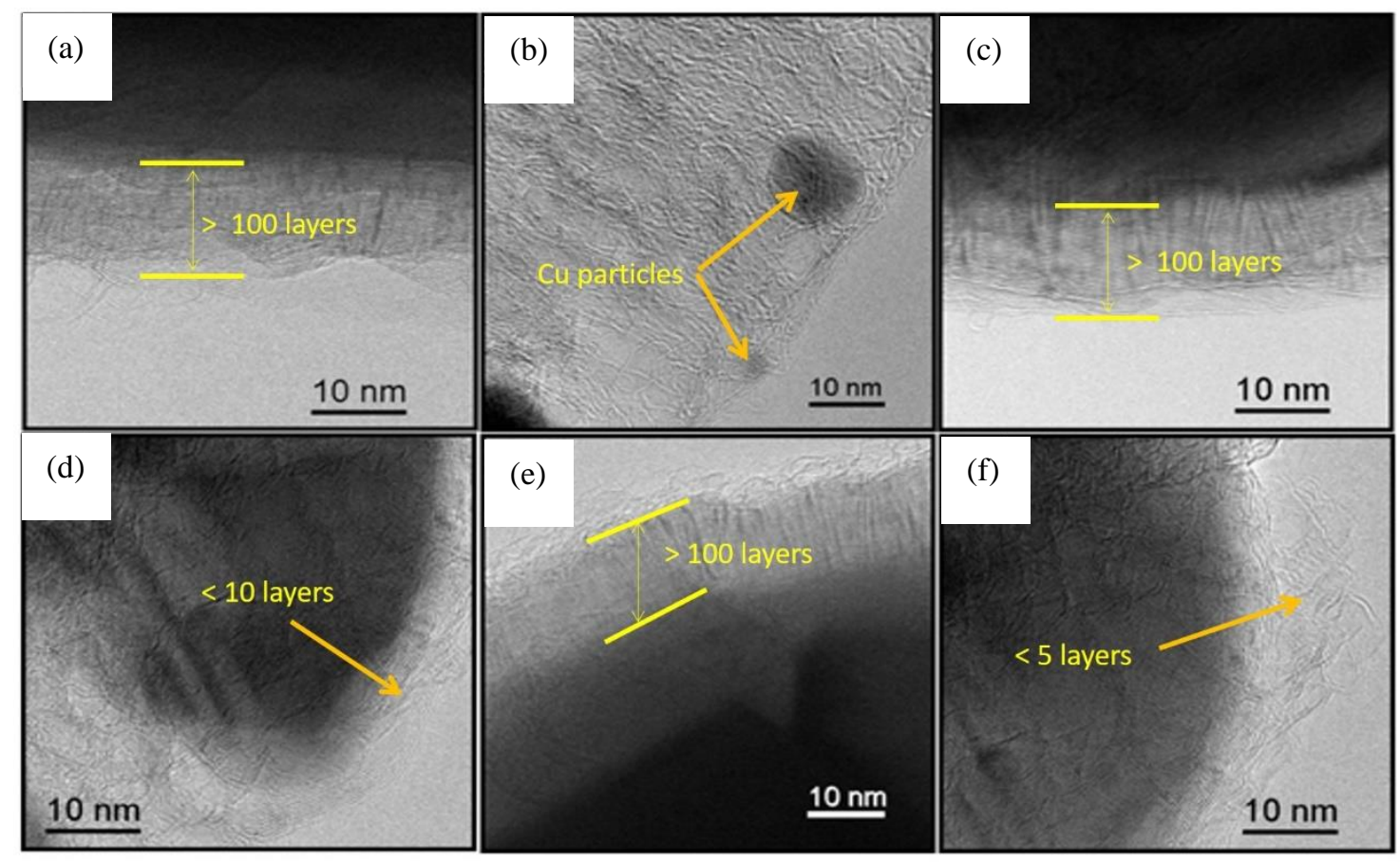

Figure 5. The high magnification image at the (a) bottom left area, (b) at the top right area, (c) at the bottom right area, (d) at the top left area, (e) at the counter probe top area and (f) at the counter probe bottom area. The graphitic layer formation formed at the outer crystalline structure of $\mathrm{Cu}$ from the high magnification TEM. Most of the graphitic layers are around $10-13 \mathrm{~nm}$.

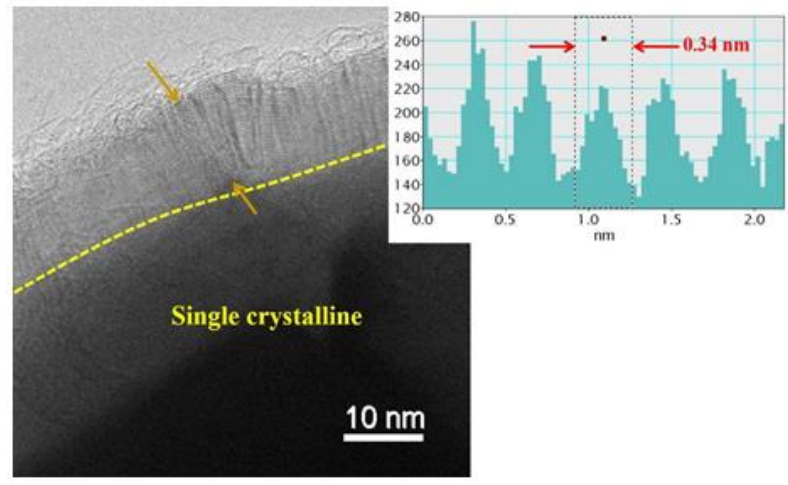

Figure 6. The distance profile result from Figure 5(e) indicating the bright region formation having thickness around $0.34 \mathrm{~nm}$. 


\section{CONCLUSION}

In summary, significant structural transformation of a $\mathrm{Cu}$ incorporated carbon nanofiber fabricated on $\mathrm{Cu}$ foil was observed using in-situ TEM facilities. After application of the bias voltage, a dramatic change in the $\mathrm{Cu}$ incorporated carbon nanofiber structure from fibrous amorphous and/or very fine crystallites to single crystal encapsulated graphitic structure was observed. The randomly dispersed $\mathrm{Cu}$ nanoparticles agglomerated and formed into single crystalline structure whilst amorphous carbon transformed into graphitic structure and covering the single crystalline particle. Joule heating was responsible for the structural change of the $\mathrm{Cu}$ incorporated carbon nanofiber.

\section{ACKNOWLEDGEMENT}

The authors would like to express their appreciation for the support of the sponsors with UTM Zamalah Scholarship, HiCOE grant (R.J090301.7824.4J202), Flagship grant (Q.J130000.2424.03G36), GUP Tier 1 grant (Q.J130000.2524.16H37) and Ministry of Higher Education Malaysia (MOHE).

\section{REFERENCES}

[1] Sumlo Iijima. Helical microtubules of graphitic carbon. Nature 1991; 354: 56-58.

[2] Tanemura M, Okita T, Tanaka J, et al. Room-temperature growth and applications of carbon nanofibers: A review. IEEE Transactions on Nanotechnology 2006; 5: 587593.

[3] Geim AK, Novoselov KS. The rise of graphene. Nature materials 2007; 6: 183-91.

[4] Wang QH, Yan M, Chang RPH. Flat panel display prototype using gated carbon nanotube field emitters. Applied Physics Letters 2001; 78: 1294-1296.

[5] De Jonge N, Allioux M, Oostveen JT, et al. Low noise and stable emission from carbon nanotube electron sources. Applied Physics Letters 2005; 87: 1-3.

[6] Liu Z, Zhang J, Yang G, et al. Development of a carbon nanotube based microfocus $\mathrm{X}$-ray tube with single focusing electrode. Review of Scientific Instruments; 77. Epub ahead of print 2006. DOI: 10.1063/1.2198793.

[7] Tan TT, Sim HS, Lau SP, et al. X-ray generation using carbon-nanofiber-based flexible field emitters. Applied Physics Letters 2006; 88: 2004-2007.

[8] Parveen S, Husain S, Kumar A, et al. Improved field emission properties of carbon nanotubes by dual layer deposition. Journal of Experimental Nanoscience 2015; 10 : 499-510.

[9] Daradkeh SI, Mousa MS. Switch-on phenomena and field emission from singlewalled carbon nanotubes embedded in glass. Applied Microscopy 2017; 47: 86-94.

[10] Dong KY, Lee YD, Kang BH, et al. Design of a multi-walled carbon nanotube field emitter with micro vacuum gauge. Nanoscale Research Letters 2013; 8: 1-6.

[11] Giubileo F, Di Bartolomeo A, Iemmo L, et al. Field emission from carbon nanostructures. Applied Sciences 2018; 8: 526.

[12] Koh AL, Gidcumb E, Zhou O, et al. Oxidation of Carbon Nanotubes in an Ionizing Environment. Nano Letters 2016; 16: 856-863.

[13] Pan ZW, Xie SS, Chang BH, et al. Very long carbon nanotubes. Nature 1998; 394 : 631-632.

[14] Ren ZF, Huang ZP. Synthesis of large arrays of well-aligned carbon nanotubes on glass. Science 1998; 282: 1105-1107. 
[15] Eatemadi A, Daraee H, Karimkhanloo H, et al. Carbon nanotubes: properties, synthesis, purification, and medical applications. Nanoscale research letters 2014; 9: 393.

[16] Ahmad I, Yazdani B, Zhu Y. Recent advances on carbon nanotubes and graphene reinforced ceramics nanocomposites. Nanomaterials 2015; 5: 90-114.

[17] Chen C, Chen Y, Zhu S, et al. Catalyst-free in situ carbon nanotube growth in confined space via high temperature gradient . Research 2018; 2018: 1-9.

[18] Xia K, Zhan H, Gu Y. Graphene and carbon nanotube hybrid structure: A review. Procedia IUTAM 2017; 21: 94-101.

[19] Wei Q, Tong X, Zhang G, et al. Nitrogen-doped carbon nanotube and graphene materials for oxygen reduction reactions. Catalysts 2015; 5: 1574-1602.

[20] Tanemura M, Ghosh P, Yusop MZ, et al. Transparent and flexible field electron emitters based on the conical nanocarbon structures. Journal of the American Chemical Society 2010; 132: 4034-+.

[21] Kim GH, Shin JH, An T, et al. Junction-free flat copper nanofiber network-based transparent heater with high transparency, high conductivity, and high temperature. Scientific Reports 2018; 8: 1-8.

[22] Wang D, Zhang Y, Lu X, et al. Chemical formation of soft metal electrodes for flexible and wearable electronics. Chemical Society Reviews 2018; 47: 4611-4641.

[23] Pan Z, Cheng F, Zhao B. Bio-Inspired polymeric structures with special wettability and their applications: An overview. Polymers 2017; 9: 32-39.

[24] Truong GT, Kim J, Choi KK. Effect of multiwalled carbon nanotubes and electroless copper plating on the tensile behavior of carbon fiber reinforced polymers. Advances in Materials Science and Engineering; 2018. Epub ahead of print 2018. DOI: $10.1155 / 2018 / 8264138$.

[25] Saleem AM, Desmaris V, Enoksson P. Performance Enhancement of Carbon Nanomaterials for Supercapacitors. Journal of Nanomaterials 2016; 2016: 1-17.

[26] Tanemura M, Okita T, Yamauchi H, et al. Room-temperature growth of a carbon nanofiber on the tip of conical carbon protrusions. Applied Physics Letters 2004; 84: 3831-3833.

[27] Yusop MZM, Ghosh P, Yaakob Y, et al. In situ TEM observation of Fe-included carbon nanofiber: Evolution of structural and electrical properties in field emission process. ACS Nano 2012; 6: 9567-9573.

[28] Yusop MZ, Ghosh P, Sasase M, et al. Structural change of ion-induced carbon nanofibers by electron current flow. Proceedings - 2010 8th International Vacuum Electron Sources Conference and Nanocarbon, IVESC 2010 and NANOcarbon 2010 2010; 43-44.

[29] Liu Y, Yan X, Lan J, et al. Phase-separation induced hollow/porous carbon nanofibers containing: In situ generated ultrafine $\mathrm{SnOx}$ as anode materials for lithium-ion batteries. Materials Chemistry Frontiers 2017; 1: 1331-1337.

[30] Yaakob Y, Kuwataka Y, Yusop MZM, et al. Room-temperature growth of ioninduced Si- and Ge-incorporated carbon nanofibers. Physica Status Solidi (B) Basic Research 2015; 252: 1345-1349.

[31] Araby MI, Rosmi MS, Vishwakarma R, et al. Graphene formation at $150{ }^{\circ} \mathrm{c}$ using indium as catalyst. RSC Advances 2017; 7: 47353-47356.

[32] Vincent P, Purcell ST, Journet C, et al. Modelization of resistive heating of carbon nanotubes during field emission. Physical Review B - Condensed Matter and Materials Physics 2002; 66: 1-5.

[33] Wang ZL, Gao RP, De Heer WA, et al. In situ imaging of field emission from 
individual carbon nanotubes and their structural damage. Applied Physics Letters 2002; 80: 856-858.

[34] Li Y, Sun Y, Jaffray DA, et al. Coulomb explosion of vertically aligned carbon nanofiber induced by field electron emission. RSC Advances 2017; 7: 40470-40479. 